\title{
PODEMOS VOLTAR DA MORTE? Algumas reflexões sobre EQM
}

\section{Can we come badk from the death? Some reflections about N D E}

\author{
José Zacarias de Souza \\ Professor da Universidade Nove de Julho (UNINOVE), Mestre em Psicologia da Universidade São Marcos, São Caetano do \\ Sul, SP - Brasil, e-mail: zacarias@ uninove.br
}

\section{Resumo}

Este artigo expõe o conceito de morte, a diferença entre morte clínica e morte vital. Um breve histórico sobre as experiências de quase morte (EQ M) e quais suas características principais. Q uais os efeitos transformadores da EQ M, ou seja, as modificações apresentadas pelos indivíduos após uma EQ M. As teorias que explicam a EQ M como por exemplo a morte cerebral, alucinação, lóbulo temporal, da falta de oxigênio e da despersonalização. E finalmente considerações finais acentuando a importância da pesquisa de EQM principalmente sobre os efeitos posteriores daqueles que passam por esta experiência.

Palavras-chave: Morte. EQ M. Transformação.

\begin{abstract}
This article exposes the concept of death, the difference between clinic death and vital death. A brief history about near death experiences (NDE) and their main characteristics. Which NDE changing effects are, or, the changes made by individuals after an NDE. The theories that explain NDE are the brain death, hallucination, temporal lobe, lack of oxygen and depersonalization. Final considerations emphasizing the importance of NDE research mainly about the subsequent effects of those who go through this experience.
\end{abstract}

Keywords: Death. NDE. Transformation. 


\section{INTRODUÇÃO}

Somente três coisas são certas: a morte, os impostos e o medo de ambos. Woody Allen

Parece que é impossível definir o que é a morte, pois se trata de um mistério que nos envolve. Diz-se que é impossível defini-la, levando em consideração um contexto mais amplo, pois é lógico que a Biologia ea Medicina definem o que é a morte, quando e como ela ocorre. Além de ser considerada um mistério, transformou-se em tabu. Antes, o tabu era o sexo, hoje, é a morte. Os médicos escondem dos doentes terminais a sua verdadeira condição, para não falar da morte. Os pais escondem-na das crianças, quando um parente morre, e falam: "ele foi viajar..." ou outra coisa parecida.

Mas, ao mesmo tempo em que a morte foi transformada em tabu, nós podemos ver uma certa banalização do tema na televisão, seja em programas de ficção (desenhos animados, filmes, novelas), seja em reportagens reais do dia-a-dia. A ficção que mostra a morte de um personagem e depois sua continuação sem explicação alguma (videos desenhos animados) traz uma insensibilidade para as crianças diante da morte, que passam, então, a ter uma visão deturpada dela. Coisa que não ocorria no século XIX, pois a morte era parte integrante da vida. Fazendo com que este episódio fosse muito mais familiar a uma criança, e com um certo entendimento do que se passava, do que ocorre atualmente. As crianças também parecem saber quando estão morrendo e não se sentem intimidadas em falar sobre 0 assunto. ${ }^{1}$ Esta deturpação com relação à morte faz com que as pessoas se afastem da necessidade de entendê-la. 0 entendimento e a reflexão sobre a morte só trariam a valorização da própria vida. Além disso, podemos observar que há muitas pessoas que relatam experiências que vivenciaram durante a morte clínica. Ou seja, foram dadas oficialmente como mortas por alguns minutos, mas conseguiram ser reanimadas por uma equipe médica. Após estas experiências elas relatam certas observações que tiveram e que são muito impressionantes. Além disso, há umamudança na forma da pessoa enfrentar a vida e aceitar a morte. Para estas experiências temos algumas explicações, embora ainda não sejam conclusivas.

\section{A morte}

A morte é um fato cercado de mistérios porque ninguém, que realmente passou por ela, voltou para relatá-la depois. Mas as observações que são feitas por pessoas que estão próximas da morte podem nos trazer alguns esclarecimentos. Uma das ciências que pode esclarecer este acontecimento é a Psicologia, porqueéumaciênciaqueestudaanatureza da mente humana. Além disso, existe 0 relato de pessoas que sofreram a morte clínica, regressando depois à vida ${ }^{2}$ como já havia mencionado.

$\mathrm{Na}$ maior parte das vezes, a pessoa que passa pela morte clínica e é reanimada não se lembra de nada. Isto não podemos estranhar, visto que ocorre diariamente conosco com os sonhos. E um fato que sonhamos diariamente, e é até necessário para mantermos a nossa saúde, mas muitas pessoas dizem que sonham raramente ou se lembram dos sonhos de uma maneira muito superficial. Por isso, que as pessoas que passam por uma EQ M ${ }^{3}$ podem desta não se recordar. Ao fazer esta observação não quero de antemão colocar as EQ Ms no mesmo patamar dos sonhos. Enquanto algumas pessoas não se lembram, outras são capazes de relembrar tudo o que lhes aconteceu e isto proporciona aspectos importantes para a compreensão do fenômeno da morte.

Se voltarmos para a história das civilizações, veremosque o homem sempreprocurou compreender estefenômeno chamado morte. Tanto que as pessoas que viveram em épocas diferentes e em lugares distantes, às vezes, sem possibilidade de comunicação entre elas, escreveram livros sobre a morte. Estes livros, embora separados pela distância de espaço ou de tempo, trazem informações muito semelhantes. Entre outros estão: o L ivro E gípcio dos M ortos, queeraum tipo delivro sagrado dosmistérios iniciáticos da Antiguidade; D e A rte Moriendi; The

\footnotetext{
1 Para maiores detalhes indico o livro de Kübler-Ross, Elisabeth. (1982), 0 n children and death. New Y ork: Touchstone,

2 Barbarin, G eorges. (1997). 0 livro da mortedoc. São Paulo: Paulus. Mood , R. (1979) A vida depois da vida. [S. l.]: Nórdica, entre muitos outros.

3 D iferentes siglas foram empregadas para definir as experiências de quase morte. Em inglês a mais conhecida éNDE (Near-D eath Experience), em português a mais conhecidaéEQM (Experiência de Q uase Morte) adotada neste texto.
} 
L amentation of $D$ ying $C$ reature, 0 rologium Sapientiae, da literatura mística medieval; Pretak handa, da literatura sagrada hindu. Do período moderno, temos: De C oelo et de Inferno, de Swedenborg; The Tibetan Book of the dead, livro da série tibetana, em que se fala da importânciadeesclarecerà pessoaqueestámorrendo sobre os processos que se passam em sua mente.

Logo percebemos que o fenômeno damorte não é só biológico mas também um fenômeno psíquico e cultural.

A ciência, principalmente a Medicina, conhecemuito bem afenomenologia externadamorte, e é capaz de determinar o momento em que ocorreu, as causas que a produziram e as consequências para o corpo biológico. Estes conhecimentos auxiliam até a desvendar crimes. É o caso da ciência forense, ramo da medicina legal, e para isso é necessário saber minuciosos detalhes sobre a morte e 0 morrer. ${ }^{4}$

Em relação aos relatos de pessoas que passaram pela morteclínica, o doutor Moody elaborou um "relato típico" dessas experiências. Vejamos um exemplo:

Um homem estámorrendo e, quando chega ao ponto de maior aflição física, ouve seu médico declará-lo morto. Começa a ouvir um ruído desagradável, um zumbido alto ou um toque de campainhas, e, ao mesmo tempo, se sente movendo muito rapidamente através de um túnel longo e escuro. D epois disso, repentinamente se encontra fora de seu corpo físico, mas ainda na vizinhança imediata do ambiente físico, e vê seu próprio corpo à distância, como se fosse um espectador. Assiste às tentativas de ressurreição desse ponto de vista inusitado em um estado de perturbação emocional.

D epois de algum tempo, acalma-se e vai se acostumando à sua estranha condição. O bserva queaindatem um 'corpo', mas um corpo de natureza muito diferente e com capacidades muito diferentes das do corpo físico que deixou para trás. Logo outras coisas começam a acontecer. Outros vêm a seu encontro e o ajudam. Vê de relance os espíritos de parentes e amigos que já morreram e aparece diante dele um caloroso espírito de uma espécie que nunca encontrou antes - um espírito de luz. Este ser pede-lhe, sem usar palavras, que reexamine sua vida, e o ajuda mostrando uma recapitulação panorâmica e chegando perto de uma espécie de barreira ou fronteira, representando aparentemente o limite entre a vida terrena e a vida seguinte. No entanto, descobre que precisa voltar para a Terra, que 0 momento de sua morte ainda não chegou. $\mathrm{A}$ essa altura oferece resistência, pois está agora tomado pelas suas experiências no pós-vida e não quer voltar. Está agora inundado de sentimentos de alegria, amor e paz. A pesar dessa atitude, porém, de algum modo se reúne ao seu corpo físico e vive.

Mais tarde tenta contar o acontecido a outras pessoas, mas tem dificuldade em fazê-lo. Em primeiro lugar, não consegue encontrar palavras humanas adequadas para descrever esses episódios não-terrenos. D escobretambém queosoutros caçoam dele, e então para de dizer estas coisas. Ainda assim, "a experiência afeta profundamente sua vida, especialmente suas opiniões sobre a morte e as relações dela com a vida" (Moody, 1979, p. 27-28).

Esses relatos são importantes porque possuem uma semelhança impressionante, além disso, existe uma quantidade enorme deles colhidos em vários países do mundo por profissionais sérios. A "coincidência" e 0 número expressivo desses testemunhos não podem ser desprezados. Mas não podemos dizer que a pessoa morreu. Ela passou, vivenciou, experimentos uma das "fases" deste processo ao qual damos o nome de morte. Por isso é necessário se fazer alguns esclarecimentos e distinguir entre o momento da morte clínica e 0 da morte vital, real.

\section{Morte clínica e morte vital}

A chamada morte clínica é a parada da respiração, daatividadecardíacae do funcionamento cerebral, mas não, a impossibilidade de uma reanimação.

É claro que não é só com a parada das batidas do coração e da respiração que se determina 0 momento da morte. Atualmente, há vários processos para se diagnosticar a morte.

A cada dia os métodos de reanimação estão sendo aperfeiçoados. E a reanimação comprova que a morte não ocorre como um fato que acontece de uma vez.

Por isto, é necessário distinguir entre 0 momento da morte clínica e o da morte vital propriamente dita. Um outro sinônimo para amorte vital é morte real, pois, neste estágio, não há

\footnotetext{
${ }^{4}$ Para maiores detalhes indico o livro de Saferstein Richard. (2000). C riminalistics: A n introduction to forensic science. Estados Unidos: PrenticeHall College.
} 
possibilidadealgumadereanimação. Todas as células do corpo morreram, não restando um único vestígio deanimação.A mortevitalé "umaparadairreversível das funçỗes vitais. [...] Em outras palavras, a 'morte' é definida como o estado do corpo do qual é impossível voltar à vida" (Moody, 1979, p. 142).

Já na morte clínica, o indivíduo ainda está no processo de morte, porque os órgãos não cessam de funcionar de uma só vez, e os tecidos destes mesmos órgãos também têm tempos diferentes de ir deixando de estar animados, ou seja, sem vida. Mas a morte é constatada porque são órgãos muito importantes para todo o organismo.

Entre o momento da morte clínica e o da morte vital há, via de regra, um espaço de tempo de aproximadamente cinco minutos, e em casos extremos esteperíodo podeserdeatétrintaminutos.

A distinção exata entre a morte clínica e a morte vital é extremamente importante estabelecer, uma vez que há dificuldade para se determinar a fronteira entre morte e vida. A morte não é algo fixo "mas um processo que se prolonga no tempo e cuja duração ninguém estáem condições de apreciar" (Sotto \& O berto, 1978, p. 47). No meio médico há controvérsias sobre a questão da definição do momento da morte. Podemos dizer que mesmo adotando o critério de morte encefálica não se pode ter uma certeza absoluta de que 0 indivíduo realmente morreu 5 .

\section{As experiências de quase morte}

Mas o que é interessante é que há pessoas que estiveram clinicamente mortas, ou seja, tiveram parada cardíaca, parada da atividade respiratória e do funcionamento cerebral e foram reanimadas. Ao serem reanimadas relatam fatos que dizem experienciar durante sua morte clínica. Estas experiências podem serverificadas em várias épocas desde a Antiguidade. Platão conta uma história, no Livro X de A República, sobre um soldado chamado Er. Após uma grande batalha, os mortos, já em estado de putrefação, foram agrupados para depois serem incinerados conforme o costume. Mas Er levantou-se da pira funerária e contou o que recordava durante o período de sua morte clínica. D esdeentão, são inúmeras as histórias. E o primeiro estudo sério destas experiências de quase morte não foi realizado por um psicólogo ou psiquiatra, mas porum geólogo do século XIX:Albert Heim (1892).

Esse interesse de Heim surgiu após uma queda que teve nos Alpes que desencadeara uma experiência mística.

Durante décadas colheu relatos de pessoas que haviam sobrevivido a acidentes sérios e principalmente de alpinistas que haviam sobrevivido a quedas aparentemente mortais. E em 1892, Heim apresentou pela primeira vez seus estudos por escrito e os leu durante a reunião do Clube Alpino Suíço. Chegou à conclusão que as experiências próximas da morte se assemelhavam entre si em $95 \%$ dos casos.

Em 1927, Sir William Barret, então professor de Física na Real Universidade de Ciências de D ublin, publicou o livro D eathbed V isions. Nesse livro relata as visões de pessoas moribundas, que viam parentes eamigos falecidose contavam histórias sobre sons de outro mundo. O utro autor que fez uma coletânea de casos de visões no leito de morte foi 0 pesquisador italiano Ernesto (1982). Essas visões no leito de morte não representam EQM e devem ser estudadas à parte. $\mathrm{O}$ que elas têm em comum é que os moribundos veem seus amigos e parentes mortos ou guias espirituais vindo ao seu encontro. 0 moribundo, também, vislumbra a outra vida vendo cenas panorâmicas de grande beleza. Embora essas pessoas não tenham passado pela experiência de viajar pelo outro mundo como naEQ M. As visões no leito de morte por sua vez são diferentes à medida que a experiência ocorre com o paciente lúcido, e ele faz o relato do que vêpara as pessoas que estão ao seu lado, portanto, a consciência do moribundo permanece "dentro" de seu corpo.

Este livro de Sir Barret despertou a curiosidade de Karlis O sis que, em 1961, junto com seus colaboradores, enviou questionários para médicos e enfermeiras dos Estados Unidos e Índia, para relatarem as experiências de pacientes moribundos. Foram reunidos um total de 877 casos eutilizou-se um computadorparaclassificareavaliar o material reunido. A pesquisa demonstrou que a visão mais comum dos moribundos era de pessoas que morreram antes delas, embora aparecessem também figuras religiosas como Cristo e outras formas de D eus, conforme a religião do indivíduo.

0 moderno interesse que os ocidentais demonstraram sobre a experiência de quase morte tem aumentado amplamente devido ao livro de Raymond A . Moody V ida depois da vida, publicado

\footnotetext{
5 Indico o texto deCícero Galli Coimbra. Morte encefálica. www.unifesp.br/ dneuro/ morteencefalica.htm (acessado em 24/ 08/ 06).
} 
em 1975. Anteriormente já mencionei um tipo de relato típico quefoi descrito das experiências colhidas pelo D r. Moody. 0 autor, médico epsicólogo, analisou 150 casos de experiências próximas da morte e entrevistou pessoalmente cerca de 50 casos de pacientes que sobreviveram à morte clínica.

Alguns traços são comuns a estas experiências, como:

a) a projeção do corpo: a pessoa tem a sensação de deixar o corpo e pairar sobre ele e depois pode até descrever os fatos que ocorreram ao seu redor;

b) movimento em um túnel: a pessoa tem a sensação de se locomover em um túnel escuro;

c) visão de luz: a pessoa se dirige ao encontro de uma luz que exerce profunda atração;

d) encontro com pessoas já mortas: são pessoas conhecidas ou não, seres sagrados, entidades não identificadas ou "seres de luz";

e) panorama da própria vida: o indivíduo experimenta um tipo de flashback, ou seja, uma revisão da própria vida, algumas vezes sob a perspectiva de outras pessoas. Isto faz com que a pessoa mude suas atitudes diante da vida quando é reanimada;

f) fronteira: aparentemente representa 0 limite entre a vida terrena e uma outra vida;

g) retorno à vida: percebe que deve voltar pois ainda há coisas por terminar. Esta decisão é voluntária.

Como vemos, esses relatos são importantes porque possuem uma semelhança impressionante, além disso, existe uma quantidade enorme deles colhidosporváriospaíses do mundo porprofissionais credenciados. A coincidência e o número expressivo desses testemunhos não podem ser desprezados. Mas não podemos dizer que a pessoa morreu. Ela passou, vivenciou, experimentou aparentemente uma das "fases" deste processo do qual damos 0 nome de morte.

Esse estudo pioneiro do Dr. Moody despertou o interesse para o assunto e fez com que novos estudos fossem desenvolvidos. D esta forma outros pesquisadores se interessaram e procuraram desenvolvernovas pesquisas aprimorando o método que fora utilizado anteriormente. Considero de suma importância as pesquisas desenvolvidas pelo Dr. Kenneth Ring e pelo Dr. Michael Sabom.

O Dr. Kenneth Ring (1980) era um respeitado psicólogo social da Universidade de Connecticut. Iniciou sua pesquisa procurando em várioshospitais locais descobrirpessoas quetivessem passado porumamorte clínica eque se recuperaram, outra forma de conseguir pessoas para a entrevista foi 0 anúncio feito em jornais. A equipe do Dr. Ring conseguiu uma amostra de 102 indivíduos. Alguns quase tinham morrido devido a complicações médicas, outros por se envolverem em acidentes de carro e um terceiro grupo que sobreviveu à tentativa de suicídio. Ao examinar os relatos que foram colhidos para a pesquisa o Dr. Ring descobriu que as pessoas haviam experienciado algumas fases que foram propostas pelo Dr. Moody, tais como: tornaram-se tranquilos diante da morte antes de deixaro corpo, passaram poralgum tipo deescuridão, depois perceberam uma luz com a qual vieram a se unir. Outra descoberta feita por ele é que a EQM não ocorre aleatoriamente. A EQ M se desdobra em vários estágios sequenciais. Q uanto mais o paciente penetra na EQ M, mais estágios ele experimenta.

Uma descoberta que merece destaque é que, emboravários dos 102 entrevistadosjátivessem ouvido falar de EQ M, estes relataram ter vivenciado com menos frequência do que os demais. D emonstrando de certa forma que $\mathrm{EQ} \mathrm{M}$ não éum produto de expectativas anteriores do indivíduo.

$\mathrm{O}$ interesseposteriordo $\mathrm{Dr}$. Ring, em relação à EQM, começou a mudar porque ele observou que algumas pessoas se transformam psicológica e espiritualmente após experienciar 0 fenômeno. Praticamente toda a pesquisa desenvolvida por ele procurou enfocar o podertransformador daEQ M, os dados coletados por esta pesquisa virou um livro com o nome Rumo ao ponto 0 mega.

Já o Dr. Sabom entrou em contato com a EQM, logo após o término de seu primeiro ano de cardiologia na Universidade da Flórida. A princípio achava-se cético, mas resolveu também fazer uma pesquisa, auxiliado por uma psiquiatra de nome Sara Kreutziger. Os dois pesquisadores cuidadosamente acompanharam 100 sobreviventes (71 homens e 29 mulheres) de crises envolvendo risco de morte. Os registros médicos foram examinados para corroborar as informações dadas pelos pacientes e depois estes foram entrevistados pessoalmente. O s pesquisadores 
logo verificaram que 61 pacientes informaram ter vivenciado uma EQM de forma bem definida incluindo a característica de deixar o corpo. Desses 100 relatos, 16 foram tidas como EQM simples enquanto que 32 pacientes descreveram viagens a outro mundo de alguma outra dimensão. Outra conclusão interessante é que a experiência parece ser independente da formação educacional ou religiosa ou de qualquer outro fator demográfico. O utro dado importante, que se assemelha ao obtido pelo Dr. Ring, é que as pessoas com conhecimento anterior sobre EQM experimentaram este fenômeno com menor frequência durante a morte clínica do que os outros pacientes. Não foi dada uma explicação do porquê de estas pessoas não experienciarem 0 fenômeno. Mas é interessante para nossa reflexão porque 0 normal seria a pessoa tendo conhecimento de como ocorre a EQM passar pela experiência, como se estivesse sido sugestionada. $\mathrm{Ou}$ seja, 0 conhecimento induziria um maior número de fenômenos, o que não ocorre.

As pesquisas realizadas por Ring e Sabom e tantos outros pesquisadores que estudaram e continuam estudando a EQM são tão extensas e complexas ficando difícil executarmos um comentário exaustivo. Há vários aspectos que são levantados nestas pesquisas que seriam interessantes serem refletidos para chegarmos a vislumbrar algo mais conclusivo sobre o fenômeno. Com certeza 0 interesse que vem despertando em tantos pesquisadores fará surgir teorias e experimentos para a verificação da EQM.

\section{Efeitos transformadores da EQM}

Háum crescentena literatura especializada que trata dos efeitos que ocorrem após a pessoa ter vivenciado uma EQM. Vimos anteriormente que após as primeiras pesquisas, o Dr. Kenneth Ring (1996) se preocupou mais em verificar as transformações que ocorriam com as pessoas após sua experiência.

Um dos estudiosos que realizou um estudo rigoroso sobre esta questão foi o médico Melvin Morse professor associado de pediatria da Universidade de Washington, estudou EQM em crianças por 15 anos. Ele desenvolveu uma pesquisa para conhecer melhor os efeitos após a pessoa ter experienciado uma EQM. Esta pesquisa resultou num livro, escrito juntamente com o jornalista Paul Perry, intitulado: Transformados pela L uz (1997), no qual eles apresentam depoimentos cientificamente comprovados de adultos que passaram pela EQM. Anteriormente o Dr. Melvin Morse (1990) havia desenvolvido um estudo sobre as vivências de criançasquepassaram pormorte clínica, apresentando depois este estudo no livro Closer to the Light.

O s efeitos posteriores a uma EQ M foram estudados através de entrevistas realizadas com as pessoas que se dispuseram a serem entrevistadas. Estas pessoas passaram por uma entrevista evários testes padronizados, que resumirei a seguir (Morse \& Perry, 1997; Ring, 1996):

a) perfil de adaptação à vida: avalia as pessoas em áreas como depressão, espiritualidade, uso de drogas, hábitos alimentares e grau de satisfação com a vida em geral;

b) Escala de ansiedade com a morte: foram usadas duas. A direta, chamada Escala Templer de Ansiedade com a Morte, que faz uma série de perguntas do tipo verdadeiro/falso tais como: "tenho muito medo demorrer", "tenho pavor de sofrer um ataque cardíaco", "sempre penso em quão curtaé a vida". A outra escala aparece implicitamente e de forma sutil ao longo das perguntas que são realizadas. Esta escala é chamada de Levantamento sobre Atitude de Vida de Reker-Peacock, que mostra sua satisfação com a vida e 0 que é importante para elas;

c) Levantamento de Valores de Greyson: determina o queéimportante para uma pessoa, tais como aptidão física, ser compreendido, oração, paz mundial, dinheiro e coisas materiais e sucesso pessoal;

d) Questionário sobreAcontecimentos Paranormais Subjetivos: este questionário foi desenvolvido pelo Dr. Neppe e ajuda a pessoa a examinar as suas percepções sensitivas e a classificar qualquer experiência que tenha tido como sendo válida ou inválida.

A pesquisa feita pelo D r. Melvin Morse foi realizada com pessoas que tiveram EQ M e sentiamse diferentes, transformadas; este grupo foi comparado com pessoas que não passaram pela 
experiência e também com um grupo que havia tido a experiência, mas era cético e não acreditava no que tinha visto. Esta pesquisa realizada com 0 grupo de controle (pessoas que não tiveram a experiência) conseguiu dados relevantes.

Após a análise de dados provenientes das entrevistas de mais de quatrocentas pessoas, o Dr. Melvin Morse descobriu que a EQM provoca mudanças duradouras na pessoa. Estas mudanças incluem: diminuição da ansiedade em relação à morte, maior gosto pela vida, inteligência mais elevada e aumento das capacidades sensitivas.

O Dr. Ring também chegou a conclusões parecidas em seu estudo que foi publicado posteriormente em seu livro E m rumo ao ponto 0 mega (1996). D essa pesquisa podemos sintetizar vários efeitos, tais como:
a) aumento de espiritualidade;
b) preocupação com os outros;
c) valorização da vida e menos medo da morte;
d) veem asi mesmo como parteintegrante do universo;
e) crença fortalecida na vida após a morte;
f) senso renovado de propósito;
g) maior confiança e flexibilidade em lidar com as dificuldades;
h) menor preocupação com status e posses materiais;
i) amor ao próximo.

Observamos que os efeitos posteriores a uma EQM parecem ser muito positivos e merecem ser estudados cada vez mais. Agora veremos como algumas teorias tentam explicar a manifestação deste fenômeno.

\section{Teorias que procuram explicara EQM}

São várias as posições dos especialistas na tentativa de explicar o fenômeno de forma racional. Nesse momento farei um resumo das teorias que podem explicar o que ocorre quando um indivíduo passa por uma experiência de quase morte durante uma morte clínica.

\section{Teoria da morte cerebral}

Esta teoria é uma das mais popularizadas, especialmente pela Dra. Susan Blackmore, psicóloga inglesa, e uma das mais famosas pesquisadoras sobre causas da EQM. O fato de que todos aqueles que experienciaram umaEQM seguirem o mesmo trajeto para a luz, atravessando estágios similares, ou seja, vivenciando os mesmos estágios, faz com que pensemos que pode ser uma viagem espiritual profunda. Mas o que se argumenta é que tudo isso não passa de mais uma função do cérebro que está morrendo. Todos os cérebros morrem da mesma maneira, dizem os céticos. É por isso que toda EQ M tem os mesmos elementos. Não é porque a pessoa que está morrendo viaja para um além bonito, mas porque os neurotransmissores no cérebro estão criando as mesmas ilusões, já que fisiologicamente todos são iguais. A EQM, portanto, seria criada em virtude da fisiologia cerebral, e não teria nada de transcendental. Susan Blackmore teoriza que as pessoas passam por essa experiência pois é 0 último impulso do cérebro para ajudar a enfrentar o trauma da morte. Já o D r. Charles Tart, professor emérito de psicologia na Universidade da Califórnia em Davis está convencido de que "existem aspectos da mente humana que simplesmente não podem ser reduzidos às explicações materialistas" (Tart, 1997, p. 131).

\section{Teoria da alucinação}

Alguns pesquisadores acreditam que as EQMs são explicadas pelas funções do cérebro. Pois dizem que ao morrer são secretadas endorfinas e hormônios que agem no sistema nervoso central para suprimirador. Masas endorfinasnão são alucinógenas e não podem recriar um estado similar a EQMs, embora possam estar envolvidas no processo, não são responsáveis pela experiência inteira.

Além disso, há muitos relatos de EQM de pessoas que não possuem problemas metabólicos ou cerebrais que levam a alucinações. Também podemos afirmar que quando a pessoa possui problemas orgânicos do cérebro, os pensamentos são obscuros, a pessoa fica com irritabilidade, agressividade, medo e com visões idiossincráticas diferentes do pensamento claro, apaziguador como ocorre com a EQM. Seriam sinais de que a EQM não está relacionada com alucinações como afirmam os céticos? Também há relatos de pessoas que passam por alucinação e EQM dizendo que existe uma grande diferença, o que veem na alucinação (acham menos real) e na EQM (algo experienciado como mais real). $O$ que foi verificado também é que indivíduos febris ou sob o efeito de drogas, quando próximos da morte, relatam menos EQM e menos 
experiência elaborada. Isso sugere que drogas ou delírios inibem a ocorrência de EQM. Vários pesquisadores (Carr, 1982; Morse, Venecia \& Milstein, 1989) estão propondo modelos neurobiológicos para explicar o fenômeno da EQ M lembrando o papel das endorfinas, serotoninas e hormônios. Devemos salientar que tais modelos são especulativos e não testados, pois os níveis de tais substâncias deveriam ser medidos durante 0 fenômeno, coisa até agora de certa forma um pouco difícil de ser realizada.

\section{Teoria do lóbulo temporal}

Algumas características da EQ M podem ocorrer em um tipo de epilepsia, que são associadas com os danos ao lóbulo temporal do cérebro, e os investigadores constataram que, estimulando eletricamente este lóbulo, podem imitar alguns elementos de EQMs, tais como o sentido das memórias da vida, embora esta fosse realmente uma característica comum de EQMs. Acreditam que 0 estresse de estar próximo à morte, ou de pensar de que está próximo à morte, pode de alguma forma estimular este lóbulo. Uma experiência realizada em 2000 com uma mulher de 43 anos sugere que a sensação de estar fora do corpo, e outras que surgem na experiência fora do corpo e também na EQM, podem ser produzidas quando 0 giro angular direito recebe estímulos elétricos.

\section{Teoria da falta de oxigênio}

Uma outra hipótese seria que a EQM ocorre como resultado da hipóxia ou anóxia no cérebro. Whinnery (1997) desenvolveu um modelo baseado no que ocorre com pilotos de avião a jato. A aceleração provoca a perda de consciência por um breve período, o que faz com que os pilotos relatem alteração da memória, ocorrência de efeitos visuais e até a visão de um túnel como na EQM. Mas há somente um relatório que foi capaz de medir os níveis de oxigênio e gás carbônico no sangue durante a EQ M e a relação entre este fenômeno e a anóxia (Sabom, 1982). É claro que esses modelos não explicam todo o fenômeno de EQM, mas podem ser utilizados para ajudar a distinguir os aspectos componentes do fenômeno que são resultados de perda de consciência daqueles que estão além deste aspecto e que são únicos da EQM.
Ainda temos que considerar que estes modelos não explicariam porque alguns pacientes podem dar relatórios completos das coisas que aconteceram em torno deles durante sua EQM. 0 D r. Michael Sabom (1982) relatou que um paciente, quando teve uma EQM, prestou atenção em seu médico executando um teste de sangue, mostrando riquezas de detalhes.

\section{Teoria da despersonalização}

A primeira tentativa moderna de explicar EQMs em termos psicológicos foi feita em 1930, por um psicólogo (Pfister, 1930) que afirmava que as pessoas diante de uma realidade desagradável, como a morte ou uma doença, tentam substituir essa realidade não aceita através de fantasias plausíveis para se proteger.

\section{Teoria da memória do nascimento}

Uma outra teoria popular é que a EQM não tem nada a ver com a morte, seriam memórias do nascimento. A pessoa estaria lembrando do momento do nascimento, ou seja, saindo do útero e chegando ao ambiente da sala de parto. Isto explicaria a passagem pelo túnel e a luz logo depois, alembrança também da acolhida pela equipe médica e pela mãe ainda na sala de parto, seria a sensação de amor e calor. Portanto, segundo essa teoria, 0 que 0 acorre no momento da morte é somente uma memória armazenada do que aconteceu quando 0 indivíduo nasceu. Mas em um artigo de Susan Blackmore (1983) é explicado que tanto as pessoas que nasceram de parto normal quanto as de cesárea relatam a mesma experiência do túnel, contradizendo estateoria, pois os nascidos decesárea deveriam ter outro tipo de memória armazenada.

\section{Teoria da vida após a morte}

Existem muitas evidências circunstanciais queaconsciênciasobreviveàmortecorporal. Embora saibamos que a ciência necessita de melhores ferramentas para compreender o que é a consciência. Talvez quando descobrirmos o que é a consciência, poderemos ter evidência científica absoluta que há uma vida após a morte. Pois com raras exceções, pesquisadores têm ignorado a questão da sobrevivência da consciência após a morte do corpo. 
O surpreendente é que os indivíduos que passaram pela EQ M descrevem com detalhes o que ocorreu a seu redor enquanto estavam inconscientes e eram socorridos. Se estão no hospital, e a equipe médica age rapidamente executando todo o procedimento médico de reanimação, estes pacientes quando se recobram do acontecido são capazes de narrar tudo nosmínimos detalhes. Jápessoasquenão vivenciaram uma EQM não conseguem saber de nada. Os pesquisadores Ring e Cooper (1997, 1999) encontraram 31 casos em suas pesquisas de pessoas cegas (algumas denascimento) quetiveram percepção visual e descreveram objetos e acontecimentos após experienciarem uma EQM. 0 que temos hoje são somente indícios mas, diante dos paradigmas científicos existentes atualmente, ainda não temos capacidade de fazer uma afirmação segura de que existe uma sobrevivência após a morte. 0 que não podemos é deixar de estudar e pesquisar esses casos.

Todas essas teorias que explicam a EQM podem ser reduzidas a três paradigmas: a) uma explicação neurofisiológica onde reunimos as teorias da morte cerebral, da alucinação, do lóbulo temporal, da falta de oxigênio; b) uma explicação psicológica onde encontramos a teoria da despersonalização, da memória do nascimento e c) a explicação transcendental que seria a teoria da vida após a morte, ou seja, a EQM seria uma forma real do homem experienciar o que é a morte e 0 que existe após esta. Embora possamos levar em consideração esses três paradigmas, até o momento não hánenhuma evidência que aponte para um deles.

\section{CON SIDERAÇÕES FINAIS}

Fica evidente que 0 assunto EQM é muito controverso. Pois, como vimos pelas teorias que tentam explicar o fenômeno, pode ser uma forma de defesa psicológica universal? São imperativos neurofisiológicos da espécie humana? $\mathrm{Ou}$ uma experiência real e transcendental? 0 que fica claro é que as hipóteses neurofisiológicas oferecem esperanças para solucionar a ponte entre experiência mística e eventos fisiológicos. Pois correlacionar 0 estado do cérebro com uma experiência não implica necessariamente que o estado do cérebro cause a experiência, 0 estado do cérebro pode alternativamentepermitiro acesso a, ou simplesmente refletir a experiência.
A investigação dos que experienciaram a EQM pode trazer alguns dados para verificarmos indiretamente a separação mente/ corpo e, portanto, sobre a possível sobrevivência da consciência. A possibilidade da existência da consciência depois da morte foi menosprezada, pois parecia incompatível com as teorias científicas existentes. No entanto, não podemos confundir os paradigmas da ciência com a realidade ou com a verdade; no máximo estes paradigmas representam modelos válidos que organizam as observações existentes. Q uando não são justificados ou não obtêm resultados científicos importantes devem ser substituídos por estruturas conceituais mais adequadas. Outras questões que devem ser estudadas e aprofundadas são as transformações ocorridas com a pessoa após a EQM. Estemeparece o aspecto mais promissor para futuras pesquisas sobre esta experiência quefascina o público em geral. As transformações ocorridas nas atitudes do indivíduo, crenças e valores e seu poder de produzir uma transformação pessoal e profunda já é um motivador muito grande para não deixarmos de lado essas inúmeras experiências, mas procurarmos uma explicação científica para a compreensão desse fenômeno chamado Experiência de Quase Morte.

\section{REFERÊNCIAS}

Barbarian, G. (1997). 0 livro da morte doce. São Paulo: Paulus.

Barrett, W. (1926). Deathbed visions. Londres: Methusen.

Blackmore, S. (1983). Birth and the OBE: An unhelpful analogy. Journal of the American Society fou Psychical Research, 77, 229-238.

Bozzano, E. (1982). Fenômenos psíquicos no momento da morte. Rio de Janeiro: Federação Espírita Brasileira.

Carr, D. (1982). Pathophysiology of stressinduced limbic lobe dysfunction: A hypothesis for NDEs. Anabiosis: The Journal of N ear-Death Studies, 2, 75-89.

Kübler-Ross, E. (1983). On children and death. New York: Macmillan.

Moody, R. (1979). Vida depois da vida. São Paulo: Circulo do Livro. 
Morse, M. L., Castillo, P., Venecia, D., \& Milstein, J. (1989). Near-death experiences: A neurophysiological explanatory model. Journal of N ear-Death Studies, 8, 45-53.

Morse, M., \& Perry, P. (1997). Transformados pela luz. Rio de Janeiro: Record: Nova Era.

Morse, M., \& Perry, P. (1990). Closer to the light. New York: Villaid Books.

Pfister, O. (1930). Schockdenken und Shockphantasien Bei Höchster Todesgefahr [Shock thoughts and fantasies in extreme mortal danger]. Zeitschrift für Psychoanalyse, 16, 430-455.

Ring, K. (1996). Rumo ao ponto Omega. Rio de Janeiro: Rocco.

Ring, K., \& Cooper, S. (1997). Near-death and out-of-body experiences in the blind: A study of apparent eyeless vision. Journal of N earDeath Studies, 16, 101-147.

Ring, K., \& Cooper, S. (1999). Mindsight: N eardeath and out-of-body experiences in the blind. Palo Alto, CA: William James Center/ Institute of Transpersonal Psychology.
Sabom, M. (1982). Recollections of death: A medical investigation. New York: Harper \& Row.

Saferstein, R. (2000). Criminalistics: Na introduction to forensic science. United States: Prentice Hall College.

Sotto, A., \& Varina, O. (1978). A vida depois da morte (novas pesquisas parapsíquicas). Lisboa: Publicações Europa América Ltda.

Tart, C. (1997). Quem sobrevive? Implicações das modernas pesquisas da consciência. In D oore, G ary. (O rg.). Explorações contemporâneas da vida depois da morte. (pp. 130-142). São Paulo: Cultrix.

Whinnery, J. E. (1997). Psychophysiologic correlates of unconsciousness and near-death experiences. Journal of $\mathbf{N}$ ear-D eath Studies, 15, 231-258.

Recebido: 16/ 10/ 2008

Received: 10/ 16/ 2008

Aprovado: 01/ 12/ 20008

A pproved: 12/ 01/ 2008 